We will first describe how digital images are coded and introduce Fourier Transform. Then we will use the analogy with X-ray diffraction to address some points about resolution (Fig. 2), about the phase problem in crystallography and the relation between Direct \& Reciprocal spaces.

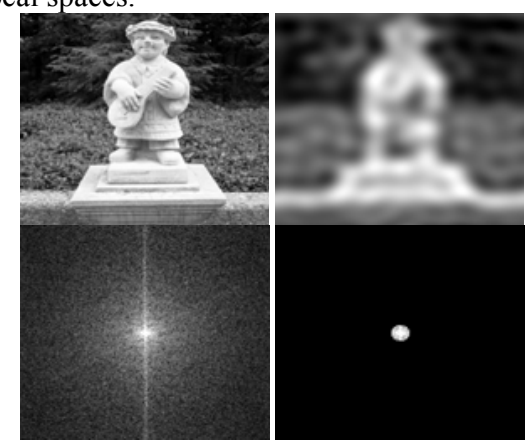

Fig. 2 Digital images and their Fourier Transforms [1] Schoeni, N. and Chapuis, G. (2006)
http://lcr.epfl.ch/page37304.html

[2] Dumas, P., Vanwinsberghe, J. and Cura, V. (2006) Crystallographic Teaching Commission of the IUCr Newsletter No.1 4-10.

[3] Gatan (2003). Gatan Inc., Pleasanton, CA, USA.

\section{MS40 O4}

Plane Symmetry in Traditional Javanese Batik

Patterns Annegret Haake , Haryani Winotosastro $^{\mathrm{b}}$, a Jaminstr., 11 b, D-61476 Kronberg, Germany.

${ }^{b}$ Tirtodipuran 54, 55143 Yogyakarta, Indonesia.

E-mail: haake.xx-tex@,t-online.de

\section{Keywords: batik art, plane symmetry, teaching aid}

Batik is a traditional method of resist cloth-dyeing in Java, Indonesia. Liquid wax is partly applied on the cotton before dyeing in cold solutions, so that the spots covered by wax remain uncoloured. In the past, only plant dyes were used. The cloths measured $1 \mathrm{~m}$ x 2,50 m and were worn as a skirt by both, men and women. At traditional occasions, the cloths are still worn in the same way. Most of the countless motifs are of pre-Islamic origin (before $15^{\text {th }}$ century). It is remarkable that all these motifs follow the laws of plane symmetry in spite of they are drawn by hand; the patterns are carried out till the natural border of the cloth. The predominant symmetry groups are $\mathrm{p} 2, \mathrm{p} 4 \mathrm{~mm}$ and $\mathrm{pm}$, but $\mathrm{p} 1, \mathrm{~cm}, \mathrm{p} 4$ and other groups with rotational symmetry 1,2 or 4 can be realized in traditional batik patterns. In opposition to that, rotational 3- and 6-fold symmetries are rarely found in real traditional patterns. In a former publication [1], it was already stated that the symmetry elements in traditional Javanese batik patterns were symbolizing the Asian philosophy models "Dualism" and "Mandala" (or Javanese "Mancapat"). It was also said that the unlimited translational symmetry of a pattern symbolized infinity, and at the same time it had a meditational effect on the batik-artist who was concentrated on her work [2]. (The waxing is a domain of women). Besides the Indian compass model "Mandala" the most important Asian philosophy-model is "Dualism"="co-existence of opposites" (male/female, dark/light, +/-, heaven/earth, yin/yang, left/right, above/below etc.). There are many examples for "Dualism" in batik designs. Dark/light is produced by the dyeing, yin/yang is representing the rotation about $180^{\circ}$, and above/below is given by the symbols for "upper and lower world" in "Semen"patterns. Left/right is found in Mancapat examples as well as in the central motifs of "Semen"-patterns. „Semen"-patterns describe the environment of the Javanese through symbolic pictures of Hinduistic origin, which are symmetrically ordered and repeated in two directions. That means, the motifs appear in fixed distances and surroundings. As well the motifs themselves, as their situation to each other had a symbolic meaning, which should be positive for the wearer. After a law of the 18th century, some patterns were dedicated to the ruler and his family, only. Those patterns were called „Larangan“ (= forbidden patterns). Educated Javanese pay attention to that, until today. The cloth, which was exclusively made for the ECM24congress, contains many ancient patterns with their names. The patchwork-look is based on real patchwork jackets, which were worn by animistic priests and later the Islamic ruler of Yogyakarta in Central Java.

[1] Haake, A., Comp. Math. Applic. Vol. 17, pp. 815-826, 1989. [2] Hardjonegoro, K.R.T., Indonesian Textiles, Proc. 1979, pp. 229-242

\section{MS40 O5}

Olex2: Making Small-Molecule Crystallography Accessible To Everyone. Horst Puschmann, Oleg Dolomanov Department of Chemistry, University of Durham,UK. E-mail: horst.puschmann@durham.ac.uk

Keywords: molecular graphics, small molecule, model building

Olex2 is a new, powerful molecular graphics program that provides a whole host of fully customizable tools for small-molecule crystallography to suit the analytical chemist and practicing crystallographer alike.

What sets it apart from most other programs of its kind is the fact that Olex2 can interact seamlessly and intelligently with refinement programs such ShelXL. Moreover, Olex2 incorporates its very own refinement program (based on the cctbx), making new areas of smallmolecule refinement accessible for the first time. Highly sophisticated refinement tools-those traditionally thought to be only usable by fully trained expert crystallographerscan be accessed and addressed intuitively, thus making building even complicated models very easy.

The User Interface to Olex2 has a high degree of redundancy: the entire program can be driven from the command line only (mostly using the syntax familiar from ShelXP), context menus (right-click) and a highly flexible and customizable GUI provide full flexibility while not compromising the underlying features.

Olex2 is available free of charge for academic use and can be downloaded from http://www.olex2.org. 